\title{
INFLUÊNCIA DA DERIVA LITORÂNEA NO DESENVOLVIMENTO DO ESPORÂO DE CAIXA-PREGOS (BAÍA DE TODOS OS SANTOS/BA)
}

\author{
ABÍLIO CARLOS DA SILVA PINTO BITTENCOURT*, FÉLIX FERREIRA DE FARIAS** \\ e GERALDO DA SILVA VILAS BOAS*
}

\begin{abstract}
THE INFLUENCE OF LONGSHORE DRIFT IN THE DEVELOPMENT OF THE CAIXA PREGOS SPIT (TODOS OS SANTOS BAY - BAHIA). Monitoring the topographic variations of beach profiles along a spit located at the southern end of the Itaparica Island (Todos os Santos Bay, Bahia), it has been possible to show that, developing since the beginning of the Holocene, this feature has stopped growing in the present. Its growth was due to longshore drift of sediments from eastern beaches, induced by NE, E and SE winds. In the present days, instead of being deposited on the spit front, the sediments are being carried into an adjacent channel by strong ebb-tide currents.
\end{abstract}

Keywords: Spit, longshore drift, beach sedimentation dynamics.

\begin{abstract}
RESUMO O monitoramento das variações topográficas de perfis praiais localizados num esporão situado na extremidade sul da ilha de Itaparica (Bafa de Todos os Santos - Bahia), cujo desenvolvimento teve início durante o Holoceno, mostrou que o mesmo parou de crescer nos dias atuais. O crescimento dessa feição geomórfica ocorreu a partir da deriva litorânea de sedimentos induzida por ventos NE, E e de SE, que transporta para aí materiais das praias arenosas situadas a leste da mesma. Atualmente, esses sedimentos, ao invés de se estocarem na parte frontal do esporão, são lançadas num canal contíguo ao corpo do esporão, por fortes correntes de maré vazante.
\end{abstract}

Palavras-chaves; Esporão, deriva litorânea, dinâmica de sedimentação praial.

INTRODUÇÃO A extremidade sul da Ilha de Itaparica, na entrada da Baía de Todos os Santos, apresenta uma feição geomórfica do tipo esporâb, com cerca de $2,5 \mathrm{~km}$ de extensão e direção SSE-NNW (Foto 1). Esta feição está solidária à ilha na sua parte sul e, no restante de seu corpo, dela separada por uma estreita laguna, em grande parte ocupada por manguesais, onde desemboca o pequeno Riacho Caixa-Pregos, ao fundo (Fig.1). Na extremidade norte do esporão, contornando-o, existe um canal, por onde o Riacho Caixa-Pregos ocorre, durante o período da baixa-mar. Segundo Martin et al. (1980) esse esporão é de idade holocênica, inferior a 5.000 anos A.P. Feicões geomórficas desse tipo são construídas pelo aporte de sedimentos trazidos pela deriva litorânea e defletidos em direção a um embaiamento (Evans 1942, Hine 1979) que, conforme as observações procedidas no decorrer do presente trabalho, carreou das praias arenosas contíguas a leste, os materiais para a formação do esporão (Fig.l), como será discutido adiante. Essas praias são constituídas de areias provenientes de terraços marinhos holocênicos, que se dispõem continuamente na região costeira por toda sua extensão (Martin et al. 1980).

O objetivo do presente trabalho foi estudar os processos pelos quais é feito o transporte para a alimentação do esporão de Caixa-Pregos. Para tanto, foram realizados levantamentos topográficos de detalhe, com a utilização de um nível, ao longo de quatro perfis transversais à praia, aqui denominados PI, P2, P3 e P4 (Fig.l), desde o pós-praia até a linha da água, no máximo possível próximo ao horário da baixa-mar. Durante 19 meses consecutivos (junho de 1987 a dezembro de 1988), foram realizados 32 levantamentos topográficos em cada um dos quatro perfis. Os dados relativos aos sentidos dos ventos e à pluviosidade durante o período de monitoramento foram coletados na Estação Meteorológica de Salvador.

O clima da Baía de Todos os Santos, segundo a classificação de Kõeppen, é do tipo Af, quente e úmido, com pluviosidade média anual de $1500 \mathrm{~mm}$ e maiores precipitações de abril a agosto (apud Santos 1962). O padrão de circulação da

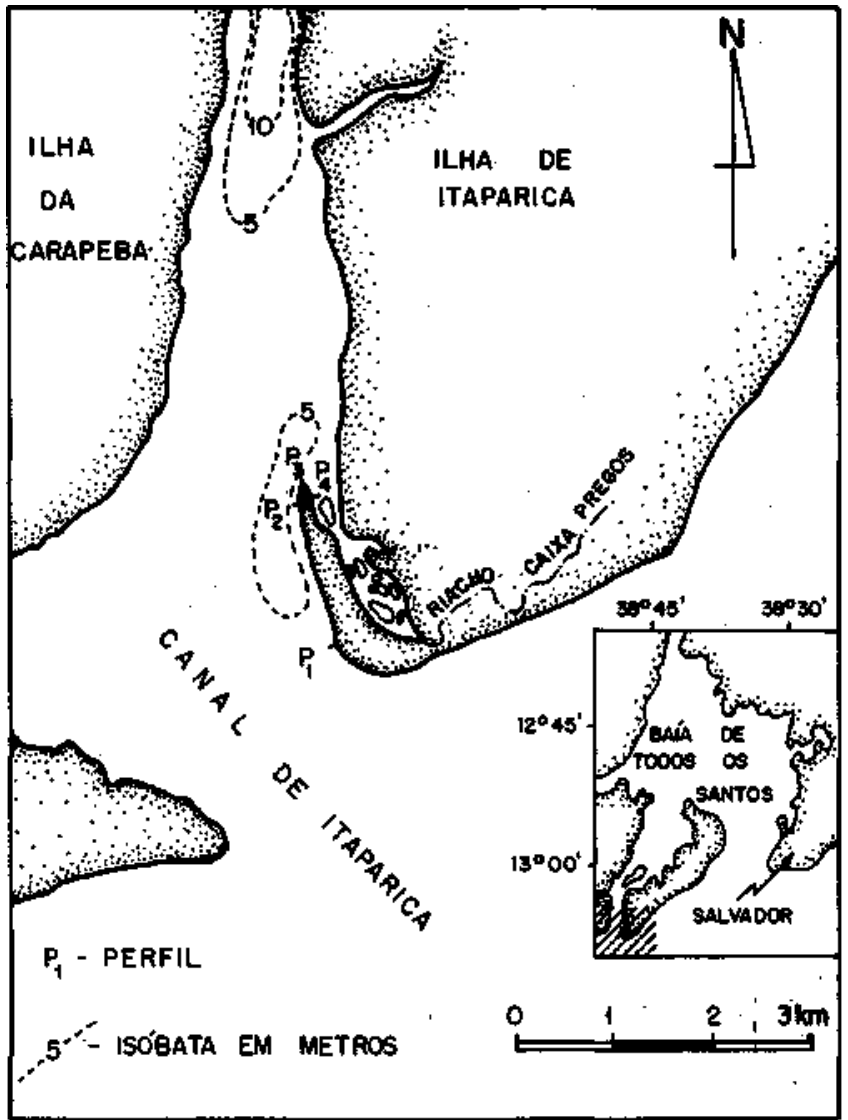

Figura 1 - Mapa de localização do esporão de Caixa-Pregos mostrando o posicionamento dos perfis

Figure I - Location of the Caixa-Pregos spit with studied transects

\footnotetext{
* Programa de Pesquisa e Pós-Graduação em Geofísica, Instituto de Geociências, UFBa, Rua Caetano Moura, 123, Federação, CEP 40210, Salvador, Bahia, Brasil

** Instituto de Geociências, UFBa, Rua Caetano Moura, 123, Federação, CEP 40210, Salvador, Bahia, Brasil
} 


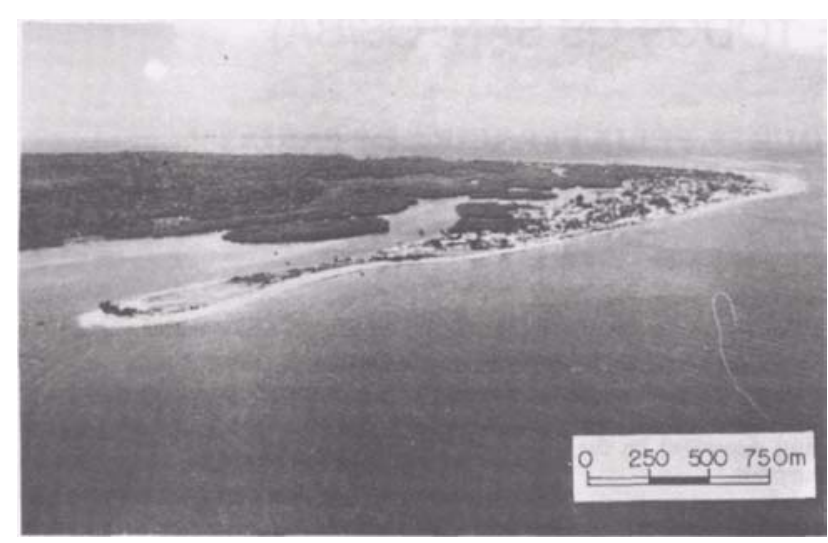

Foto 1 - Vista aérea do esporão de Caixa-Pregos

Photo 1 - Aerial photograph of the Caixa-Pregos spit

região é controlado pelas massas de ar geradas pela célula de alta pressão do Atlântico Sul e pelos avanços periódicos da Frente Polar Atlântica (Bigarella 1972). Há uma predominância dos ventos alísios (NE-E-SE) que, de maneira geral, sopram regularmente durante todo o ano (Santos 1962). Esses ventos são formados pelas migrações sazonais da zona de divergência da célula de alta pressão do Atlântico Sul: durante o inverno, localizada a sul de Salvador, ela gera ventos provindos de SE a E e, no verão, situada a norte de Salvador, ventos provenientes de NE a E (Dominguez 1984). Durante o outono e o inverno a região passa a sofrer a influência de frentes frias relacionadas à Frente Polar Atlântica em seu avanço para latitudes mais baixas, quando se intensificam as chuvas, geralmente acompanhadas de ventos provindos de S e SSE (Seplantec 1978). Os ventos de S, embora não muito freqüentes, são os mais fortes, atingindo velocidades médias de $5 \mathrm{~m} / \mathrm{s}$ (Diretoria de Hidrografia e Navegação-DHN 1976). De modo geral, os ventos do quadrante SE apresentam velocidades médias anuais de $4 \mathrm{~m} / \mathrm{s}$ (DHN 1976). Os ventos de $\mathrm{E}$ e NE são os mais fracos, com velocidades médias anuais de $3 \mathrm{~m} / \mathrm{s}$ (DHN 1976). As marés na região de Salvador são semidiurnas, alcançando um máximo de 2,6 m (DHN 1988).

VARIAÇÕES NOS REGIMES DE VENTOS E DE CHUVAS NA BAÍA DE TODOS OS SANTOS DURANTE O PERÍODO DE JUNHO DE 1987 A DEZEMBRO DE 1988 O comportamento dos ventos na Baía de Todos os Santos durante o período de monitoramento é mostrado na figura 2A. Por esta figura pode-se constatar que, durante o período em apreço, houve uma maior freqüência de ventos provindos de $\mathrm{E}$ e SE, com uma certa predominância do último. Aproximadamente, os ventos de E predominaram de outrubro de 1987 a fevereiro de 1988 e de meados de outubro a dezembro de 1988, enquanto que, os de SE, de junho a setembro de 1987 e de meados de janeiro a meados de outubro de 1988. Ventos provindos de S, que aparecem em terceiro lugar na ordem de freqüência, se concentraram entre junho e agosto de 1987 e entre março e julho de 1988, com maior freqüência no último período. De uma maneira esparsa, apareceram ainda ventos provenientes de NE, com uma ligeira concentração entre os meses de outubro e dezembro de 1987 e 1988. Por fim, esporadicamente, ocorreram também ventos de W e SW. Quanto à pluviosidade (Fig. 2B), os meses de maior intensidade foram os dê junho a julho de 1987 e de março a julho de 1988, períodos de chegada de frentes frias.

INFLUÊNCIA DO REGIME DE VENTOS NA DERIVA LITORÂNEA DE SEDIMENTOS PARA O ESPORÃO DE CAIXA-PREGOS Os ventos que ocorrem com fre- qüência significativa na Baía de Todos os Santos, provindos de E, SE, S e NE, promovem a formação de frentes de ondas que, vindas do mar, alcançam a extremidade sul da ilha de Itaparica com diferentes direções. Essas ondas, seja durante a chegada de frentes frias, erodindo, ou durante os períodos de calma, construindo, têm energia suficiente para modelar de maneira significativa um perfil praial, como demonstrado por Farias et al. (1985) e Bittencourt et al. (1987) numa praia localizada na costa atlântica de Salvador, próxima ao esporão de Caixa-Pregos (Fig.l, encarte). Ao alcançarem a extremidade sul da Ilha de Itaparica, todavia, adentrando o estreito canal onde está localizado o esporão de Caixa-Pregos (Fig.l), essas ondas são refratadas, perdendo altura e energia, conforme mecanismo já bem conhecido na literatura, como pode ser visto em Komar (1976), por exemplo. Essa perda de energia, desse modo, faz com que as ondas geradas pelos ventos de $\mathrm{S}$, associados às frentes frias, percam as suas características destrutivas, bem documentadas na costa atlântica de Salvador (Farias et al. 1985). Todavia, à semelhança das ondas geradas pelos ventos de E, SE e NE, as ondas provindas de sul ainda assim conseguem exercer um significativo papel modelador do perfil praial, mediante a formação de uma deriva litorânea induzida pela componente das mesmas paralela à praia.

Como pode ser visto nas figuras $3 \mathrm{~A}$, B e C, todos os principais ventos que ocorrem na região induzem a formação de uma deriva litorânea no sentido da extremidade sul da ilha de Itaparica para a ponta do esporão. Nas praias que se estendem para nordeste da extremidade sul da Ilha de Itaparica, a deriva tem um sentido para sudoeste quando da predominância de ventos provindos de NE, E e SE (Fig. 3A), até, variando no sentido de $\mathrm{S}$, a situação representada na figura $3 \mathrm{~B}$, na qual ela é inexistente. A partir daí, até os ventos eminentemente de $\mathrm{S}$

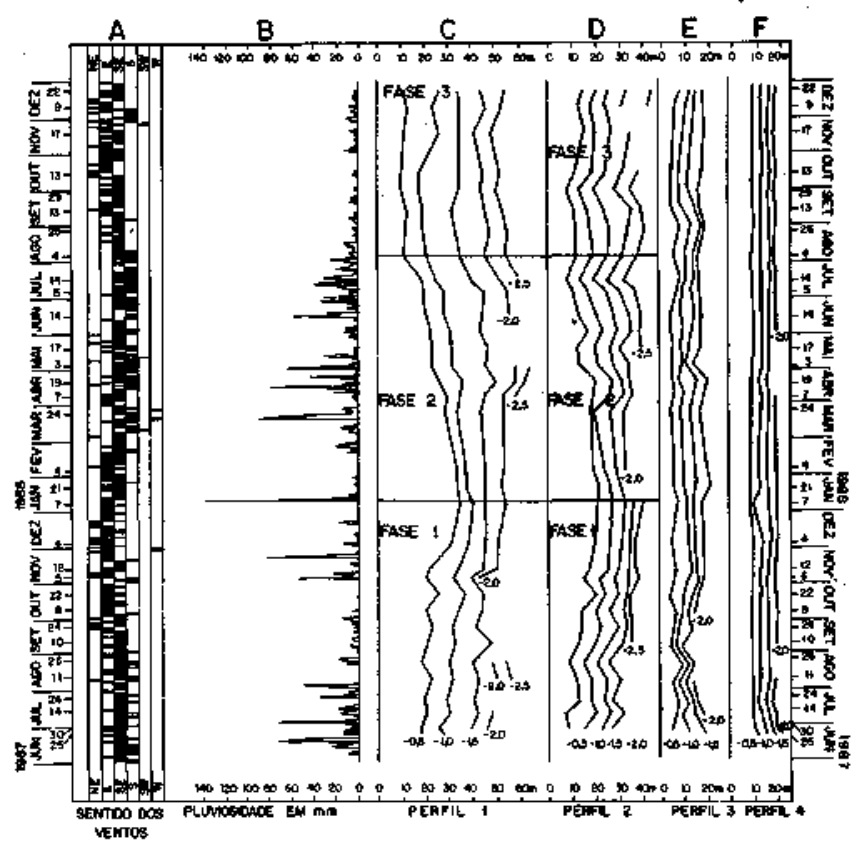

Figura 2 - A. sentido dos ventos na Baía de Todos os Santos; B. pluviosidade na Baía de todos os Santos; C,D,E e F. diagramas de linhas de contorno para os perfls 1,2,3, e 4, respectivamente. Os contornos ligam pontos de cotas iguais na superficie da praia, em metros, medidas ao longo do tempo em relação a um datum que passa pelo pôs-praia Figure 2 - A. wind direction in Todos os Santos Bay; B. rainfall variation in Todos os Santos Bay; C,D,E and F. isopleth diagrams showing variations in beach surface elevation through time measured form a horizontal datum that intercepts the beach prism in the backshore. Lines connect equal elevation points relative to this datum. Diagrams depict variations on profiles 1,2,3 and 4 

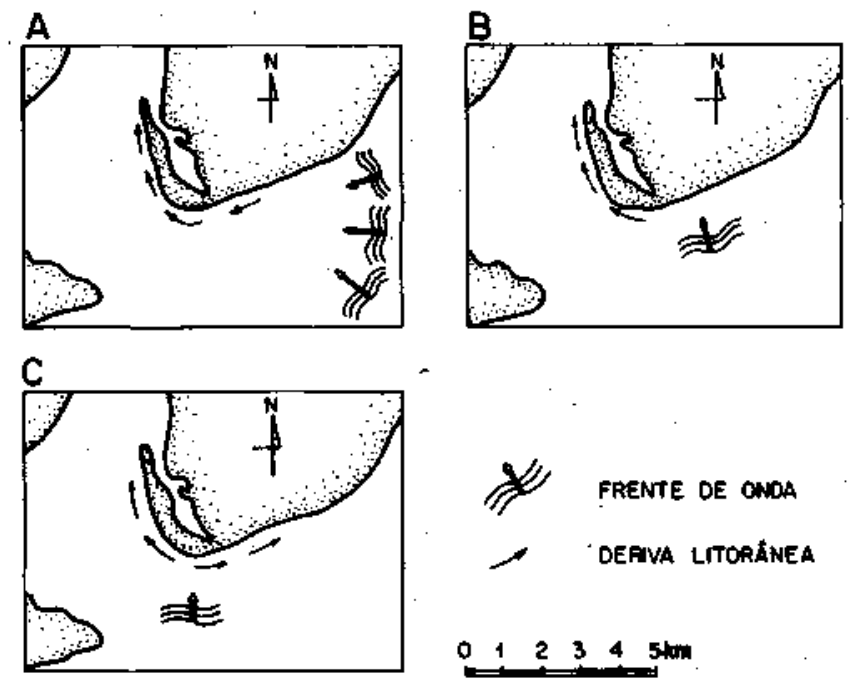

Figura 3 - Mapas esquemâticos dos padrões de deriva litorânea gerados por ventos provindos de nordeste, leste e sudeste (A), sul-sudeste (B) e sul (C)

Figure 3 - Schematic charts showing the longshore drift of sediments induced by winds blowing from NE, E and SE(A), SSE(B) and S(c)

(Fig. 3C), ela passa a ter um sentido inverso, para nordeste. As derivas provocadas pelos ventos de NE, E e SE (Fig. 3A) promovem a alimentação do esporão, uma vez que 'carreiam para o mesmo materiais provenientes das praias a leste. Já as derivas induzidas pelos ventos de SSE e de S (Figs. 3B e C) vão erodir o esporão.

FASES EROSIVAS E CONSTRUTIVAS As modificações topográficas verificadas nos perfis P1, P2, P3 e P4, ao longo do tempo de monitoramento, são mostradas nos gráficos das figuras $2 \mathrm{C}$ a F. Esses gráficos foram contraídos, para cada perfil, tomando-se como datum comum a todos um plano horizontal passando pela região do pós-praia. Assim, para cada perfil, foram sendo lançadas, a partir de seu início no póspraia, as distâncias horizontais correspondentes às cotas dos diferentes pontos de quebra da declividade do perfil da praia, medidas em relação ao referido datum, que foram sendo assumidas ao longo do tempo. A partir daí, foram então traçados diagramas de linhas de contorno que unem pontos de cotas iguais. Esses diagramas mostram que apenas os perfis 1 (Fig. 2C) e 2 (Fig. 2D) apresentam mudanças significativas ao longo do tempo, enquanto que os perfis 3 (Fig. 2E) e 4 (Fig. 2F) sofreram muito pouca movimentação de material, praticamente inexistente no último.

De maneira geral, os perfis 1 e 2 apresentam três fases bem marcadas, com os limites entre as mesmas coincidentes nos dois perfis: duas fases construtivas (fases 1 e 3 ) e uma destrutiva (fase 2) (Figs. 2C e D).

\section{DISCUSSÃO E CONCLUSÕES À exceção dos perfis}

3 e 4 (Figs. 2E e F), nos quais a movimentação de materiais na face da praia foi muito pouca (quase inexistente no perfil 4), sem apresentar, inclusive, qualquer relação aparente com 0 regime de ventos responsável pela geração da deriva litorânea, os demais evidenciaram significativas variações no perfil praial (Figs. 2C e D). Essas variações, consubstanciadas em bem marcadas fases erosivas e construtivas (Figs. 2C e D), guardam uma estreita relação com o regime de ventos. Assim, pode-se observar que a fase construtiva 1 , nos perfis 1 e 2 (Figs. 2C e D), corresponde, de modo geral, a um período em que houve pouca ocorrência de ventos provindos de $\mathrm{S}$, se comparados aos de E e SE (Fig. 2A). Essa fase pode ser subdividida em dois trechos, com limites coincidentes nos dois perfis, que mostram, em termos da velocidade de construção do perfil "praial, características ligeiramente distintas entre si. O primeiro trecho, de 25 de junho a 25 de agosto de 1987 (Figs. 2C e D), apresenta uma baixa velocidade de construção, quase nula no perfil 2. Já no segundo trecho, de 25 de agosto de 1987 a 7 de janeiro de 1988, a velocidade de contração é maior, quase igual nos dois perfis. Pela figura 2A constata-se que no primeiro trecho há uma maior predominância de ventos de SE e de S e, no segundo, de ventos de E, SE e NE. Desse modo, a maior velocidade de crescimento no segundo trecho deve estar relacionada à predominância de ventos de $\mathrm{NE}$ e E que, como mencionado anteriormente, promovem o aporte de materiais para o esporão (Fig. 3A). Já no primeiro trecho, cujo crescimento é mantido basicamente às custas dos ventos de SE, francamente promovedores de tal processo (Fig. 3A), a velocidade de crescimento é mais lenta devido à presença de ventos de S. Assim, a ação desses ventos, por provocarem a erosão do esporão (Fig. 3C), contrapõe-se à dos ventos de SE, atenuando a velocidade de construção do perfil praial. Vale ressaltar ainda que, durante a faixa de tempo correspondente ao primeiro trecho, os ventos do quadrante SE podem ter tido um sentido, em alguns dias, mais para SSE, de tal forma que se aproximassem da situação representada na figura 3B. Essa situação, à semelhança daquela provocada pelos ventos de $\mathrm{S}$, tenderá também a retardar o crescimento praial.

Se comparada à fase construtiva 1 , a fase erosiva 2 , em ambos os perfis 1 e 2 (Figs. 2C e D), corresponde, de maneira geral, a uma faixa de tempo em que houve: a. uma menor incidência dos ventos francamente construtores de E e NE e b. uma bem maior freqüência de ventos provindos de $\mathrm{S}$ (Fig. 2A). À semelhança da fase 1 , também a fase 2 pode ser subdividida, nos dois perfis, em dois trechos distintos, com diferentes velocidades de erosão. O primeiro, com limites coincidentes nos dois perfis, de 7 de janeiro a 24 de março de 1988 , apresenta uma menor velocidade de erosão do que o segundo, que vai de 24 de março a 4 de agosto de 1988 (Figs. 2C e D). A característica.erosiva da fase 2 , pelos motivos explicados anteriormente, deve estar relacionada, de uma maneira mais dependente, à predominância dos ventos de $\mathrm{S}$ em relação aos de E (Fig. 2A). A par disso, deve também ser levada em conta, nessa fase, a possibilidade dos ventos de SE poderem ter tido sentidos aproximados aos da situação representada na figura $3 \mathrm{~B}$, também propicia a erosão. A menor velocidade de erosão verificada no primeiro trecho dos dois perfis (Figs. 2C e D) deve estar associada à menor incidência de ventos $\mathrm{S}$ e à maior freqüência de ventos $\mathrm{E}$ do que no segundo trecho (Fig. 2A). Ainda em relação ao primeiro trecho, em que pese os ventos de $\mathrm{E}$ serem mais freqüentes do que os de $\mathrm{S}$, o perfil praial mesmo assim é erodido porque é provável que a ação erosiva dos últimos tenha sido somada a de ventos de SE em situações que se enquadram à da figura $3 \mathrm{~B}$.

Quanto à fase três nos perfis 1 e 2, observa-se que, de uma maneira geral, houve recorrência das condições meteorológicas que prevaleceram durante o segundo trecho da fase 1 (Figs. 2A, C e D), o que de forma semelhante importou numa época construtiva para os perfis 1 e 2 . Essa fase construtiva, todavia, em ambos os perfis, foi de menor amplitude do que a do segundo trecho da fase 1 , o que pode estar relacionado ao fato de que, na fase 3, se comparada à fase 1, há uma menor incidência de ventos provindos de $\mathrm{E}$, eminentemente construtores, e uma maior freqüência de ventos de SE (Figs. 2A, C e D) que podem ter, eventualmente, se aproximado mais da situação mostrada na figura 3B e, desse modo, propiciado alguma erosão no esporão.

Por fim, ressalte-se que o presente trabalho aponta no sentido de que o esporão de Caixa-Pregos, nos tempos atuais, parou de crescer. Este fato pode ser constatado pelo exame da figura $3 \mathrm{E}$, na qual se vê que, durante o período de monitoramento, apesar de ter havido pequenas construções e erosões, $o$ 


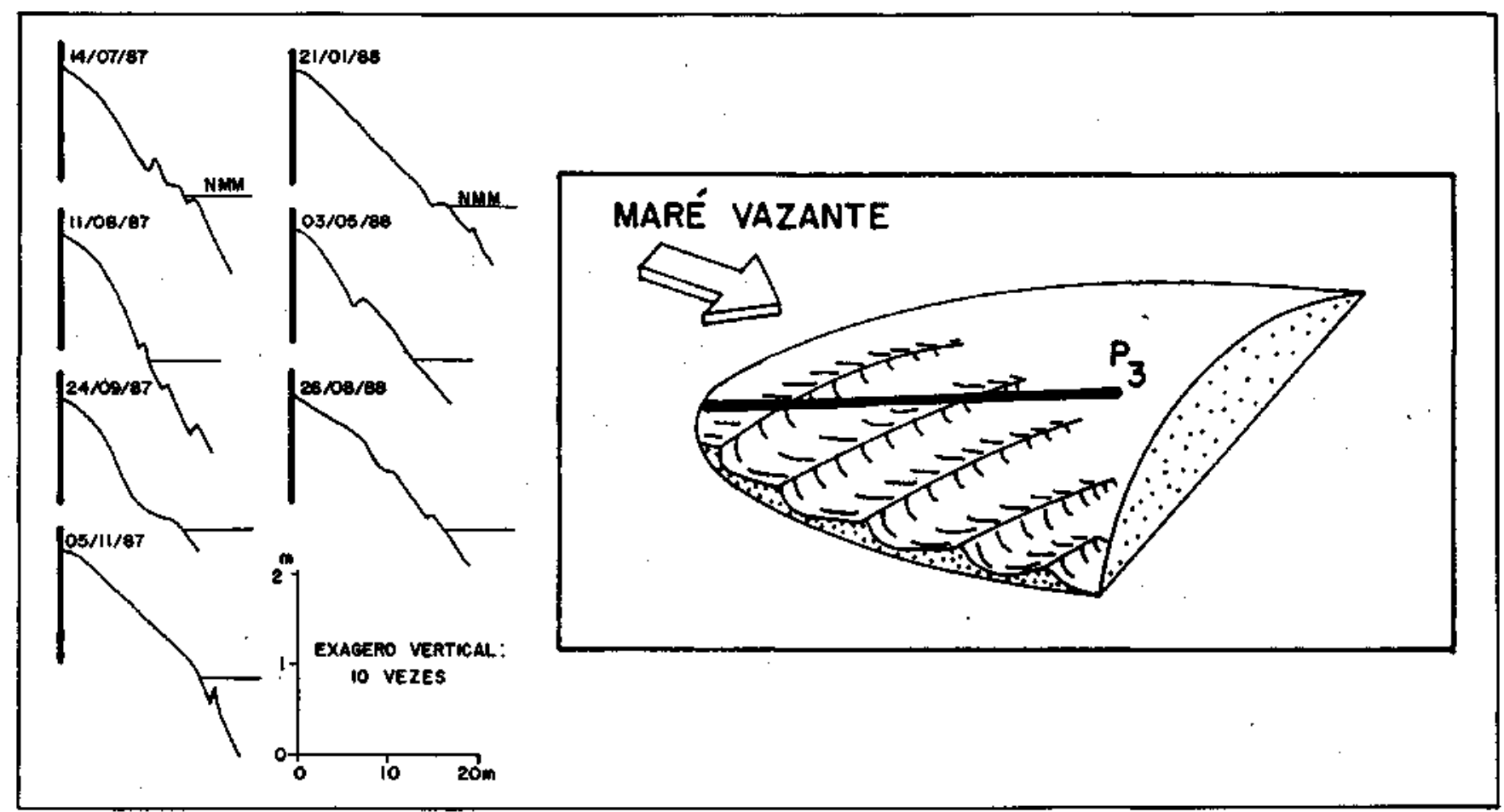

Figura 4 - Perfis Praiais significativos da localidade 3 (P3, Fig.1) mostrando a presença de marcas de ondulação por corrente de grande porte. O encarte mostra um esquema do posicionamento dessas formas de leito em relação à direção do perfil 3

Figure 4 - Significant beach profiles from site 3 (P3, Fig. 1) showing large ripple marks. The inset shows the positioning of these bedforms in relation to $\mathrm{P} 3$ direction

perfil praial 3, localizado exatamente na parte frontal do esporão (Fig. 1), não apresentou, como resultado final, nenhum crescimento. Este fato demonstra que os materiais que estão sendo permanentemente carreados para a parte frontal do esporão pela deriva litorânea não permanecem aí estocados. Provavelmente, estes materiais estão sendo lançados, a partir da ponta do esporão, no canal contíguo ao mesmo (Fig. 1), pelas correntes formadas pela maré de vazante. A efetividade do poder dessas correntes para efetuar tal transporte pode ser atestada pela presença extensiva na face da praia, ao longo de quase todo o período de monitoramento, de marcas de ondulações por corrente, de grande porte, na região frontal do esporão contígua ao canal acima mencionado. Pela figura 4, que mostra uma série de levantamentos topográficos realizados na ponta do esporão (Fig. 1 perfil 3), constata-se que essas formas de leito são assimétricas, apresentando alturas entre 15 $\mathrm{cm}$ a $20 \mathrm{~cm}$. Quanto aos seus comprimentos, os mesmos aparecem exagerados na figura 4 (na realidade, são em torno de
Im), uma vez que o perfil 3 não é perpendicular às ondulações (ver encarte na figura 4). Por fim, o encarte na figura 4 mostra ainda que a assimetria das ondulações reflete claramente $o$ sentido da corrente de maré de vazante (ver também o posicionamento do perfil 3 na figura 1). A possibilidade de que parte dos materiais carreados pela deriva litorânea, sob o efeito da refração das ondas, viesse a contornar a ponta do esporão para então se depositar, é descartada pelos resultados do monitoramento realizado no perfil 4 (Figs, 1 e 2F). Nesse sentido observa-se que, praticamente inexistiu qualquer tipo de acréscimo de material no citado perfil durante o período de investigações.

Agradecimentos Os autores externam seus agradecimentos à professora Zelinda Margarida de Andrade Nery Leão, pela versão do resumo para o inglês, e a um revisor anônimo, pelas proveitosas críticas e sugestões apresentadas.

\section{REFERÊNCIAS BIBLIOGRÁFICAS}

BIGARELLA, JJ. 1972. Eolian Environments - their characteristics, recognition, and importance. In: J.K. RIGBY and W.L.HAMBLIN eds. Recognition of Ancient Sedimentary Environments, 16:12-64. (Sepm. Special Publ.)

BITTENCOURT, A.C.S.P.; FARIAS, F.F. ZANINI Jr., A. 1987. Reflexos das variações morfodinâmicas praiais nas características texturais dos sedimentos da praia de Armação, Salvador, Bahia Reviras. Geoc., 17:276-282.

DIRETORIA DE HIDROGRAFIA E NAVEGACCÃO-DHN. 1976. Roteiro da costa leste do Brasil. Ministério da Marinha. 284p

DIRETORIA DE HIDROGRAFIA E NAVEGACCAO-DHN. 1988. Tábuas das marés para o ano de 1988 - costa do Brasil e portos estrangeiros. Ministério da Marinha. 22p.

DOMINGUEZ, J.M.L. 1984. Patterns of wave induced longshore drift during the Hohcene as a paleoclimatic indicator. 19p. (Inédito).

EVANS, O.F. 1942. The origin of spits, bars, and related structures. $J$. Geol., 50:846-863.

FARIAS, F.F.; BITTENCOURT, A.C.S.P.; ZANINI Jr., A.; DOMINGUEZ, J.M.L. 1985. Variações temporais e espaciais na dinâmica de sedimentação da praia de Armação, Salvador, Ba. RevBras. Geoc., 15:48-54.

HINE, A.C. 1979. Mechanisms of berm development and resulting beach growth along a barrier spit complex. Sed.,26:333-35l.

KOMAR, P.D. 1976. Beach processes and sedimentation.Nev/Jersey, Prentice-Hall. 429p

MARTIN, L.; BITTENCOURT, AC.S.P.; VILAS BOAS, G.S.; FLEX̉OR, J.M. 1980. Texto explicativo para o mapa geológico do Quaternário costeiro do Estado da Bahia. Escala 1 :250.000. Bahia, CPM, SME/BA. 57p.

SANTOS, R.F.A. 1962. Chuvas na Bahia. Bah'a. DNOCS.

SEPLANTEC. 1978. Atlas cünatológico do Estado da Bahia, documentário sintese. Salvador, Centro de Planejamento da Bahia (CEPLAB). 191p. 